\title{
The Effect of Peer Evaluations on Student Reports of Learning in a Team Environment: A Procedural Justice Perspective
}

\author{
Lynn Bowes-Sperry \\ Western New England College \\ Deborah L. Kidder \\ Towson University \\ Sharon Foley \\ Drexel University \\ Anthony F. Chelte \\ Midwestern Sate University
}

\begin{abstract}
Student peer evaluations are a form of student voice. However, research has not determined if the positive outcomes associated with voice in other contexts (e.g., judicial system, workplace) are also present in the student team environment. We collected data from student teams in business schools in the United States and Hong Kong to examine the ways in which peer evaluation influences student teams. Our results indicate that for students working on team projects, peer evaluations have implications for their learning.
\end{abstract}

\section{An Overview of Teams and Fairness}

Business schools have embraced the team concept as an important instructional element in the delivery of the curriculum. This has provided students with opportunities to "experience" teamwork as part of their formal academic training and career preparation. In addition to the potential for helping students develop interpersonal skills and the understanding of different perspectives (Goldfind, Laybourne, MacLead \& Stewart, 1999; Michaelson \& Razook, 1999; Chelte, 2003), team projects may also enhance student learning of course content (Tinto, 1999). However, evidence strongly suggests that assigning team projects is not sufficient. Students benefit most from a design that incorporates team-building skills and skills required to overcome barriers to effectiveness (Feichtner \& Davis, 1985; Bacon, Stewart, \& Silver, 1999; Bolton, 1999; Ettington \& Camp, 2002; Tonn \& Milledge, 2002).

One potential barrier to an effective student team project is a perceived lack of fairness or sense of justice surrounding the project. As noted by Houston and Bettencourt (1999), issues of fairness are relevant to many aspects of education including grades, evaluative feedback, access to information, and distribution of workload. Classroom concerns regarding justice issues have received some attention in the literature but this generally concerns the fairness of instructor-imposed aspects such as exams, grading, 
etc. (Chory-Assad, 2002; Houston \& Bettencourt, 1999; Ghorpade \& Lackritz, 1998; Marsh \& Overall, 1980; Rodabaugh \& Kravitz, 1994). Furthermore, such research has not been informed by the extensive body of knowledge on the topic of procedural justice (see Chory-Assad, 2002 for an exception).

The failure to rigorously examine issues of fairness in the classroom using a procedural justice framework represents an important gap in the collaborative learning literature. Procedural justice refers to the extent to which the procedures used by authorities in making allocation decisions are perceived as fair (Greenberg, 1990; Lind \& Tyler, 1988; Thibaut \& Walker, 1975). One of the best-known aspects of procedural justice is voice (Korsgaard \& Roberson, 1995; Lind \& Tyler, 1988; Shapiro, 1993). Research indicates that even when people receive unfavorable outcomes, they perceive the allocations as fairer when they are allowed voice or input into the decision than when they are not (Lind, Kurtz, Musante, Walker, \& Thibaut, 1980), and this in turn leads to positive outcomes such as organizational citizenship behavior (Fahr, Podsakoff, \& Organ, 1990).

In the context of student team projects, one important allocation decision to be made by "authorities" (or in this case, professors) is to determine how grades earned on team projects will be allocated to individual students. In most courses, it is the professor who will determine the procedure for making this allocation decision. For example, professors could determine individual student grades for team projects with or without input from the students' team members, i.e., they could allocate the same grade to all team members or use peer evaluation to make distinctions among team members.

The course-level procedure of peer evaluation is a form of student voice. However, research has not determined if the positive outcomes associated with voice in other contexts (e.g., judicial system, workplace) are also present in the student team environment. In the present study, we address this gap in the literature. First, we seek to determine if peer evaluation procedures surrounding team projects influence students' reports of their learning. Second, we seek to examine both instrumental and relational procedural justice effects of peer evaluations. The instrumental model suggests that voice is important because it allows individuals the opportunity to obtain a desired goal (e.g., Thibaut \& Walker, 1975), whereas the relational

(relational procedural justice is also referred to as non instrumental procedural justice and interactional justice) model proposes that voice is important (even when it has no instrumental value) because it signals to individuals that they are respected members of their group or community (e.g., Lind \& Tyler, 1988; Tyler, Degoey, \& Smith, 1996). Finally, we will discuss practical implications for educators and provide recommendations for future research. 


\section{Hypotheses}

\section{Course-Level Procedures And Student Reports Of Learning}

Empirical studies (e.g., Alexander \& Ruderman, 1987; Bidder, Chang, \& Tyler, 2001; Folger \& Konovsky, 1989; Lind \& Tyler, 1988; Moorman, 1991) have demonstrated the connection between organizational procedures used in decision-making and employees' reactions such as trust in management, intentions to turnover, approval of supervisor, job satisfaction, attendance, conformance to work procedures, and organizational citizenship behaviors. Past research also suggests that procedural justice affects performance (cf Greenberg, 1990 and Lind \& Tyler, 1988).

Research on teams in the workplace has also found connections between procedures (and thus perceived fairness) and group productivity and satisfaction (Colquitt, Noe, \& Jackson, 2002; Cooper et al., 1992; Mossholder, Bennet, \& Martin, 1998). Perhaps the findings most relevant to this study come from Chory-Assad (2002), who found that students' perceptions of procedural justice were predictive of their motivation and affective learning, and Stubbline (2001) who found that teams with peer evaluations have higher levels of workload sharing, voice, cooperation, performance, and member satisfaction. Similarly, in the student team environment, we expect to find a relationship between the percent of grade determined by peer evaluation and positive student outcomes such as increased learning.

Hypothesis 1: Percent of grade determined by peer evaluation will be positively related to student reports of learning in a team environment.

Course level procedures, team individualism-collectivism, and instrumental justice effects

Organizational justice research has found that differences in fairness perceptions are often associated with individualism-collectivism (Colquitt, Noe, \& Jackson, 2002; Konovsky, 2000). Individualism is characterized by putting personal interests ahead of group needs (especially when group needs conflict with personal desires) whereas its opposite, collectivism, is characterized by allowing group interests to supersede those of the individual (Wagner \& Moch, 1986). According to Tata (2001), it is necessary to understand the level of student individualism-collectivism when making predictions regarding the extent to which justice considerations are relevant to students. Although her work focused on the perceived fairness of grading, there are reasons to expect that student individualism-collectivism will provide insight into the effects of other forms of justice in the classroom, such as the opportunity to use voice.

As described previously, research on procedural justice indicates that procedures (such as voice) may be important because they are instrumental or because they are relational. In the student team environment, procedures that allow students to achieve grades with which they are satisfied would be considered instrumental. We expect that the course level procedure of peer evaluation will have instrumental value for some 
students. Liden, Nagao and Parsons (1985) found that students often complain of unfairness because they believe that group work results in grade inequities. When peer evaluations are available, students have the ability to use them to penalize social loafing members, thus restoring equity among team members.

Research indicates that the ability to restore equity is important to individualists because they are motivated by self-interest (e.g., Early, 1989; Olson, 1971). Since they tend to be competitive, individualists want to receive recognition for their contributions, and thus would be likely to use peer evaluations to make distinctions between themselves and other team members. While merely having the opportunity to evaluate their peers is important, it is likely that individualists' satisfaction with their ability to restore equity will increase as the percent of grade determined by peer evaluations increases.

Furthermore, without procedures such as peer evaluation, which increase student accountability, students on individualistic teams may social loaf when working in a team environment because they will not be penalized for their lack of contribution. This social loafing is expected to increase as the percent of grade determined by peer evaluation decreases. In as much as peer evaluations increase students' contributions to the team project, we expect students to perceive that their team has performed well. These expectations should, in turn, lead to increased satisfaction with anticipated grade. Finally, even if peer evaluations do not decrease actual social loafing, they may decrease perceived loafing within the team. Mulvely, Bowes-Sperry, and Klein (1998) found that student teams with lower levels of perceived loafing were more effective than those with higher levels.

Alternatively, the satisfaction with anticipated grade of students working on collectivistic teams is less likely to be impacted by a percent of grade determined by peer evaluation. When working in teams, collectivists tend to be driven by social considerations more so than by task considerations (Gibson \& Zellmer-Bruhn, 2001), and tend to view the team as a team rather than an aggregation of individuals (e.g., Wagner, 1995). Therefore, students working on collectivistic teams are less likely to be concerned with making distinctions among individuals on the team, i.e., they are less likely to use peer evaluations to reduce the grade of their team members. This notion is supported by research that finds collectivists to be receptive to team-based rewards (Kirkman \& Shapiro, 2001). In the student team context, such satisfaction with team-based rewards would be likely to take the form of grade satisfaction.

In addition to satisfaction with team-based rewards, collectivists perform better under conditions of shared responsibility (e.g., on student team projects) whether or not they are held personally accountable for the results of their work (Early, 1989; 1993).

Therefore, the contributions of students working on collectivistic teams are not likely to be improved by the introduction of peer evaluations or by increasing the percent of grade determined by peer evaluation. These high levels of effort should translate into higher satisfaction with anticipated grade. 
Hypothesis 2: Team individualism-collectivism will exert moderating effects such that percent of grade determined by peer evaluation will have greater influence on satisfaction with anticipated grade for students working on individualistic teams than for those working on collectivistic teams.

Course level procedures, team individualism-collectivism, and relational justice effects

Research on relational procedural justice has typically examined interpersonal treatment initiated by someone with authority such as a manager (Bies, 2001; Bies \& Moag, 1986; Korsgaard, Roberson, \& Rymph, 1998). For example, how does a manager communicate the fact that an employee will not receive a pay raise this year? Does he or she provide adequate justification and show concern for the employee or simply state that no raise will be forthcoming? In the context of the academic classroom, this focus on authority translates to the manner in which faculty members treat students.

In addition to interpersonal treatment by those in positions of authority such as professors, interpersonal treatment by members of a student's team also seem relevant when examining the effects of procedural justice on perceived student learning in a team environment. In most courses, once the professor has established the team project, authority is delegated to students to allocate the tasks and manage the processes involved in completing the project. In accordance with the group-value model of procedural justice (Lind \& Tyler, 1988), procedures that allow students to feel that they are respected and valued members of their team would be considered relational. In addition to arguing that the percent of grade determined by peer evaluation will have instrumental effects on students, we also expect that it will exhibit relational effects. Research on procedural justice finds that both instrumental and relational effects often co-exist (e.g., Lind \& Tyler, 1988). As with instrumental justice effects, theory suggests that relational justice effects stemming from peer evaluation will be stronger for individualistic teams than for collectivistic teams.

Theory suggests a positive relationship between percent of grade determined by peer evaluation and relational justice within individualistic teams. By definition, individualists prefer to work alone rather than in a group because they do not have the social motivations for teamwork that collectivists have (Gibson \& Zellmer-Bruhn, 2001; Wagner, 1995). Therefore, they are more likely to put their own self-interest ahead of that of the team. This may include engaging in behaviors that indicate a lack of respect for other team members. For example, since individualists are concerned with maximizing performance (Gibson \& Zellmer-Bruhn, 2001), they are more likely than collectivists to force their ideas (at least when they believe that their ideas are superior to those of other team members) on their team members. They believe that the potential outcome (a better project) is more important than the process used to achieve that outcome (disrespectful communications).

However, as the percent of grade determined by peer evaluation increases, students have more to lose by exhibiting negative behaviors in team environments. Team 
members who feel that their opinions and ideas were not considered or valued have the ability to negatively impact the grade of a disrespectful or demeaning team member. For students on individualistic teams, this may serve as the motivation to be more considerate and respectful of the personalities, ideas and contributions of their team members.

Conversely, we do not expect percent of grade determined by peer evaluation to improve relational justice effects for collectivistic teams. As mentioned previously, collectivists have social motivations for working in groups (Gibson \& Zellmer-Bruhn, 2001) and therefore do not require extrinsic motivation (e.g., the threat of a reduced grade) to treat their team members as valued members of the team. Furthermore, the tendency of collectivists to subordinate personal goals to in-group goals (Triandis et al., 1985; 1988) and to behave more cooperatively (Cox, Lobel \& McLeod, 1991) renders them less likely to push the team to accept their ideas (thus, respecting the opinions of other team members and treating them in a just manner).

Hypothesis 3: Team individualism-collectivism will exert moderating effects such that percent of grade determined by peer evaluation will have greater influence on relational justice for students working on individualistic teams than for those working on collectivistic teams.

Instrumental procedural justice outcomes and student reports of learning

As described previously, satisfaction with anticipated grade can be considered an instrumental outcome of the procedure of peer evaluation (e.g., Kane \& Lawler, 1978; Murphy \& Cleveland, 1991; Wexley \& Klimoski, 1984). While we expect that satisfaction with anticipated grade will be an outcome of percent of grade determined by peer evaluation, we also expect that it will be an antecedent of student reports of learning. More specifically, we hypothesize that the positive relationship between percent of grade determined by peer evaluation and student reports of learning (predicted in Hypothesis 1) will be mediated by satisfaction with anticipated grade. The instrumental model of procedural justice views the fulfillment of self-interest as a mediator between a given decision-making procedure and judgments regarding the fairness of that procedure. In other words, when deciding if they think a procedure is fair, individuals will ask "Does this procedure serve my self-interest?" In this study, the process would unfold like this - If increasing the percent of grade determined by peer evaluation improves my grade, then it is a fair procedure (otherwise it is not). However, while it is interesting to know whether or not students perceive peer evaluations as fair, we are concerned with students' judgments regarding the extent to which working on a team has improved their learning. We depict the instrumental model of student learning in Figure 1. 


\section{Figure 1}

\section{Procedural Justice Effects on Student Reports of Learning}

\section{Instrumental Model}

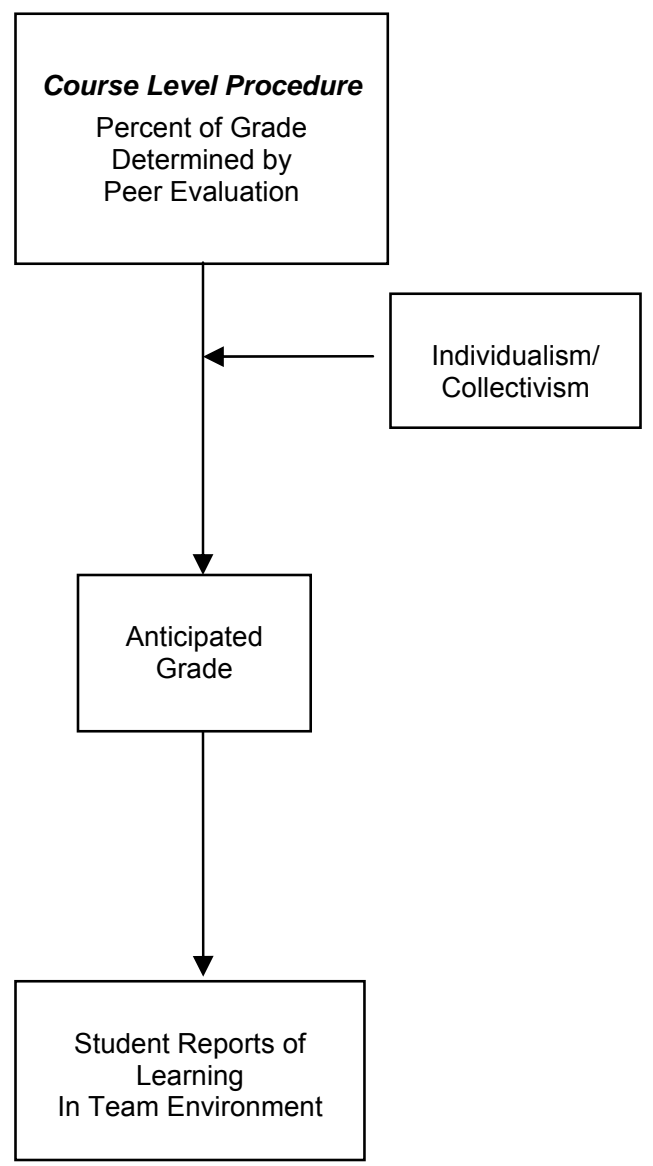

Relational Model

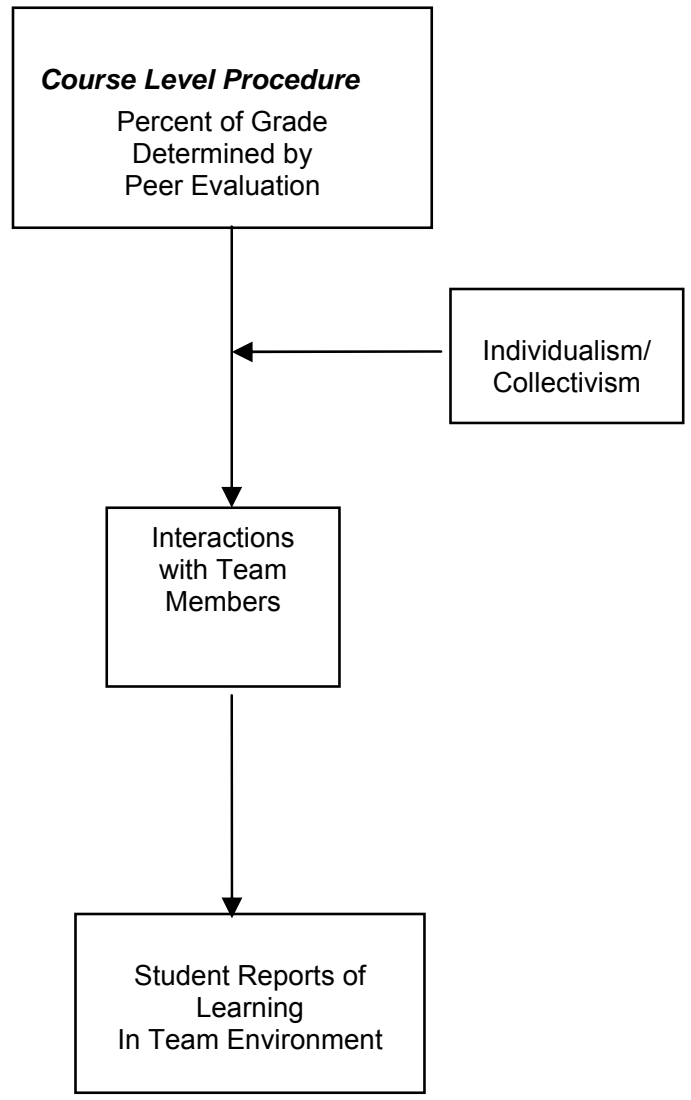

In accordance with cognitive dissonance theory (Festinger, 1957), individuals who hold conflicting beliefs will experience a state of anxiety referred to as cognitive dissonance, which they seek to reduce. Beliefs are defined as the linkages that people establish between an attitude object and various attributes (Fishbein \& Ajzen, 1975). In this study, two beliefs of interest are the extent to which students believe that the use of teams to complete course work (an attitude object) is related to (1) grades, and (2) learning. Another relevant belief is the extent to which students believe that grades (another attitude object) are related to learning. In most educational institutions, grades are used as the primary indication of student learning. A disconnect between grades and learning is extremely problematic (among other reasons) because it indicates that educational institutions are not accomplishing their objectives and that students' accomplishments will not be accurately acknowledged.

In accordance with the instrumental model of procedural justice, students anticipating or receiving poor grades on projects that they believe demonstrate high levels of learning 
will experience cognitive dissonance. There are several methods they may use to reduce this dissonance. First, they may argue that the procedure used for grading is unfair, thus attempting to persuade the instructor to change their grade. Alternatively, they may revisit their assessment of their own learning on the project - "I thought I learned a lot from doing this project, but I guess I didn't." Either method allows students to reestablish the link between grades and learning. Peer evaluation may also lead to less cognitive dissonance, particularly where there is satisfaction with the anticipated grade. However, where there is discontinuity between grades and the student's expectation, the student may reduce dissonance by adjusting his or her perception of the peer evaluation process itself.

Hypothesis 4: The instrumental outcome of satisfaction with anticipated grade will mediate the relationship between percent of grade determined by peer evaluation and student reports of learning in a team environment.

\section{Relational procedural justice outcomes and student reports of learning}

As with instrumental procedural justice, we hypothesize that the positive relationship between percent of grade determined by peer evaluation and student reports of learning (predicted in Hypothesis 1) will be mediated by interactions within the team that show respect for team members. The relational model of procedural justice views feelings of dignity as a mediator between a given decision-making procedure and judgments regarding the fairness of that procedure. In other words, when deciding if they think a procedure is fair, individuals will ask "Does this procedure make me feel that I am a valued member of the team?" In this study, the process would unfold like this - If increasing the percent of grade determined by peer evaluation makes me feel respected, then it is a fair procedure (otherwise it is not). Once again, we are interested in issues of learning or performance rather than fairness judgments. We depict the relational model of student learning in Figure 1.

Research indicates that relational procedural justice is positively related to employee performance (Greenberg, 1990; Lind \& Tyler, 1988; Robbins, Summer, Miller \& Hendrix, 2000). We expect this to be the case for student performance or learning as well. In accordance with the group value model of procedural justice (Lind \& Tyler, 1988), being treated respectfully is important to individuals because it indicates to them that they are valued members of the group or community. Teams experiencing higher levels of relational justice (e.g., respect) are likely to be more cohesive. Group cohesiveness has been found to be positively associated with better communication, cooperation, and performance (Mullen \& Cooper, 1994; Shaw, 1976). In a study of teams in higher education, team cohesiveness was found to have a significant and positive influence on team member satisfaction and motivation (Robbins and Fredendall, 2001). We expect that team cohesiveness will also lead to perceptions of improved student learning because it will encourage teams to spend quality time as a team, thus resulting in synergistic effects. In addition to fostering team cohesiveness, relational procedural justice within a team is also likely to improve the dedication of team members to the goals of the team. For example, O'Reilly and Chatman (1986) found that feeling 
connected to a group was positively associated with extra-role behaviors. In this study, extra-role behaviors, such as staying late to work on the team project, should indicate higher levels of learning.

Hypothesis 5: The relational outcome of interactions within the team will mediate the relationship between percent of grade determined by peer evaluation and student reports of learning in a team environment.

\section{The relative strength of instrumental and relational procedural justice}

As described previously, instrumental procedural justice outcomes reflect one's ability to obtain some desired end (such as a grade with which one is satisfied). Alternatively, relational procedural justice outcomes convey to individuals that they are respected and valued members of a community or group (Lind \& Tyler, 1988). Research on procedural justice effects indicates that relational procedural justice is typically a better predictor than instrumental procedural justice (Chory-Assad, 2002; Folger \& Konovsky, 1989; Robbins et al, 2000). We expect to see the same pattern in the student team context.

Hypothesis 6: Relational procedural justice will have a stronger effect than instrumental procedural justice on student reports of learning in a team environment

\section{Methods}

\section{Sample and Research Design}

Data for this study were drawn from courses taught at one institution in the Northeast United States and one in Hong Kong. For the U.S. sample, School of Business courses offered during one semester were identified by examining the schedule of courses. Faculty members who were using team projects in these courses were identified by examining syllabi on file with the Dean's office and through follow-up e-mails. Those using team projects were asked to participate in the study. Data was collected for 32 out of 43 courses in which team projects were being used. This represents a response rate of 74 percent. For the Hong Kong sample, one of the authors contacted two faculty members in the School of Business to participate in this study because they were known to use team projects in their courses. Both faculty members agreed to participate and data was collected for all nine of their courses.

Both students and faculty members completed written questionnaires in class sometime during the last two weeks of the semester. Questionnaires were administered at the end of the semester in accordance with research by Watson and Michaelson (1988: 509 ) which found that interaction behaviors among students working on team projects "were much more statistically predictive of levels of performance at this point."

Two-hundred sixty-three teams were surveyed during the semester. The number of respondents per team averaged just over three, with a range from two to ten 
respondents. After excluding cases with missing values, the final sample size was 761 , of which $31.5 \%$ were Hong Kong students, and the remaining $68.5 \%$ were from the United States. The sample demographics are: $45 \%$ female; $57.8 \%$ Caucasian, $31.3 \%$ Asian, $6 \%$ Hispanic, and less than $2 \%$ each African-American, Native American, and Multi-racial; the average age was 22.5, ranging from a low of 18 to a high of 53; the subjects had on average 2.8 years full-time work experience and 2 years part-time work experience; approximately $21 \%$ of the sample had worked as part of a team at work.

\section{$\underline{\text { Measures }}$}

The means and correlations for the variables used in our analyses can be found in Table 1.

TABLE 1

Means, Standard Deviations and Correlations

Variables $^{1}$

1. Percent of grade determined by Peer Evaluation

2. Team-level measure of Collectivism

3. Individual-level Satisfaction Anticipated Grade

4. Team-level measure of Team Interactions

5. Individual-level Perceived Student Learning $\mu \quad$ S.D. 1

$5.28 \quad 5.89$

$\begin{array}{lll}4.69 & 0.76 \quad .08^{*}\end{array}$

$\begin{array}{llll}5.55 & 1.07 & -.01 & .06\end{array}$

5.55

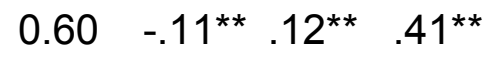

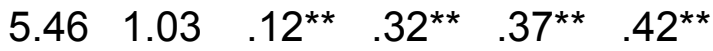

$\mathrm{N}=761$ individuals, 263 groups, 41 courses

${ }^{*}=p<.05 \quad{ }^{* *}=p<.01$

Dependent variable. Student Reports of Learning was a 5-item scale developed for this study. Each item was rated by student subjects on a 1-7 Likert-type scale. An example of one of the items is "Working in a group improved my understanding of the concepts covered in class." A principal axis factor analysis of the 5 items extracted one factor with an eigenvalue exceeding 1 . We created one variable by averaging the items (alpha=.89). Although this variable is an individual level variable, interrater reliability for the sample is high (.94), which means that we do have strong agreement within teams across the sample as a whole about learning

Independent variable. Data on what percentage of the final grade was determined by Peer Evaluation was collected from the instructors for each course to avoid issues of common method bias and to ensure accuracy. Instructors reported the percentage, from 
$0-100$.

Moderator variable. Our measure of Collectivism was drawn from Wagner (1995), which was designed to measure the value attached to working alone versus working with a group. (As noted by Early (1989), although individualism-collectivism is a multidimensional construct, researchers often use a single dimension that is most relevant to their particular study For example, he used subordination of individual goals to in-group goals in his examination of social loafing in work teams) The student subjects rated the three-item measure on a 1-7 Likert-type scale. Even though all three items loaded on one factor, one item was dropped because it decreased the alpha of the scale to .76. The average of the two items (alpha=.83) was coded such that a high score indicated a high valuing of group work (and thus a high level of collectivism). In order to test if it was acceptable to aggregate this variable to the team level, the within-group interrater reliability of each item was calculated (James, Demaree, \& Wolf, 1984). Each item was over .9, making it possible to aggregate the items by using the team average for each item.

FIGURE 2

Moderation effect of Individualism-Collectivism

on the Relationship Between Peer Evaluation and Interactions within the Team

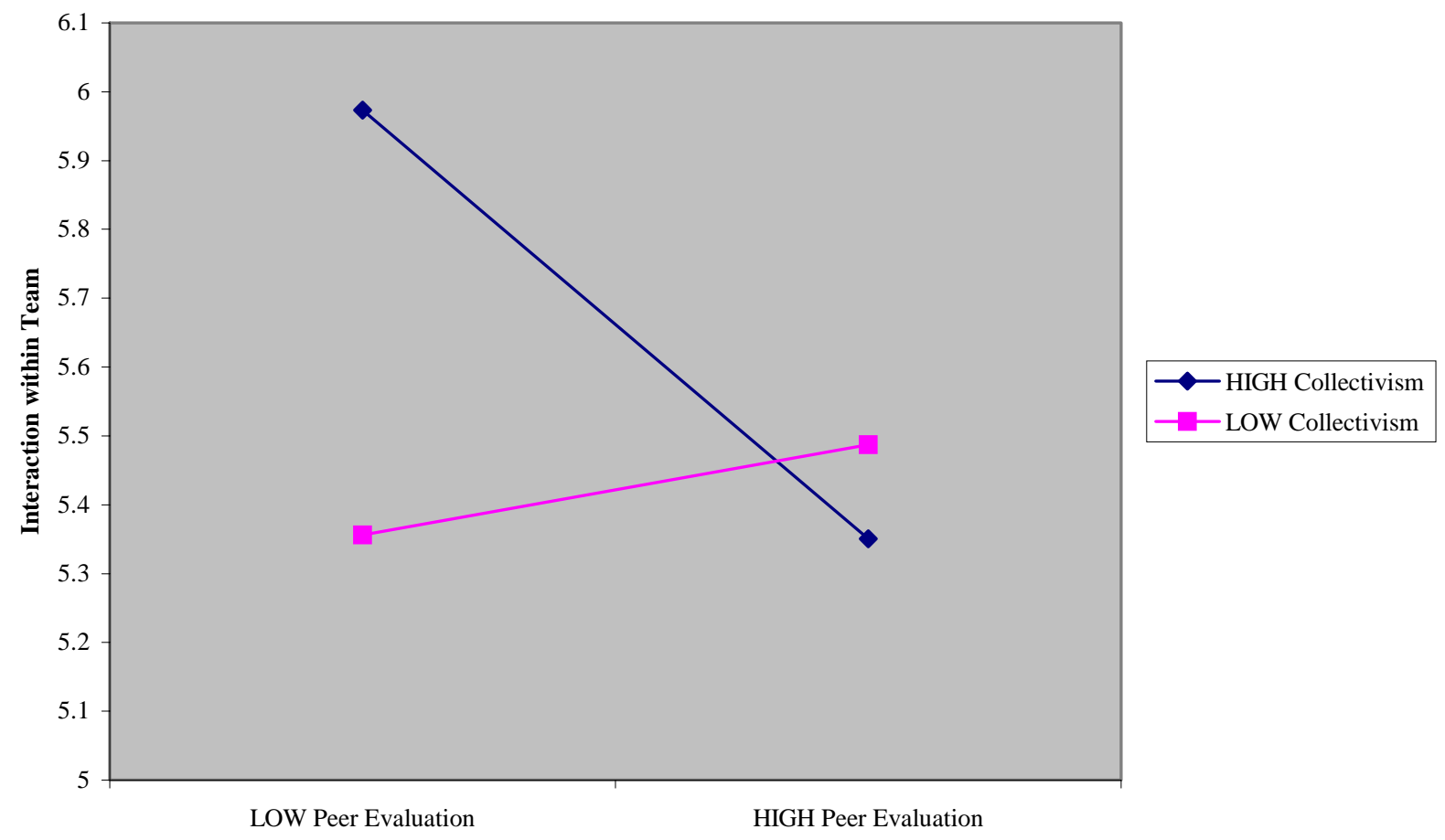

Mediator variables. Both the instrumental and relational justice items were measured with a 1-7 Likert-type scale. Satisfaction with anticipated grade was measured with two items developed for this study, "I think that the grade I will receive for my group 
assignments will be fair", and "I am satisfied with the grade I expect to receive on the group assignment." The two items were averaged and had a coefficient alpha $=.79$. The variable of Interactions within Teams was measured with Niehoff and Moorman's (1993) 5 -item scale designed to assess interactional justice but was adapted to reflect the student team environment. The items were aggregated to the team level of analysis after the inter-rater reliability was calculated (all items were above .9), the team average was used for each item and then one variable was constructed from the average of the items (coefficient alpha $=.92$ ).

\section{Analyses}

The main-effect hypotheses were tested using multiple OLS regression analyses. The moderator hypotheses were tested using multiple hierarchical OLS regression analyses, with the main effects added in the first stage and the interaction effects added in the second stage. The significant moderator interactions were analyzed with the procedures outlined by West, Aiken, and Krull (1996). The moderator variable was centered and high and low scores calculated using one standard deviation above and below the mean. The mediation analyses were based on the analysis of mediation discussed in Baron and Kenny (1986). There are three steps to follow when testing for mediation. First, a significant relationship between the explanatory variable and the dependent variable must exist. Second, a significant relationship between the mediating variable and the dependent variable must exist. Third, when both the explanatory variable and the mediating variable are included in the model, the previously significant relationship between the explanatory variable and the dependent variable should become insignificant.

\section{Results}

Hypothesis one suggested that there would be a significant and positive relationship between the percent of the course grade determined by peer evaluation and student reports of learning. This hypothesis was supported (see Table 2, column 1). 
TABLE 2

Regression Results ${ }^{1}$

\begin{tabular}{llll}
\hline Variables & $\begin{array}{l}\text { H1 } \\
\text { DV: Perceived } \\
\text { Student } \\
\text { Learning }\end{array}$ & $\begin{array}{l}\text { H2 } \\
\text { DV: Anticipated } \\
\text { Grade } \\
\text { Satisfaction }\end{array}$ & $\begin{array}{l}\text { H3 } \\
\text { DV: Interaction } \\
\text { within Teams }\end{array}$ \\
\hline $\begin{array}{l}\text { Step 1 } \\
\text { Peer Evaluation }\end{array}$ & $.12^{* *}$ & n.s. & $-.11^{* *}$ \\
$\quad$ Individualism-Collectivism & & n.s. & $.11^{* *}$ \\
& & & \\
Adj-R & & n.s. & .01 \\
F & 12.01 & n.s. & $8.71^{* *}$ \\
\hline
\end{tabular}

\section{Step 2}

Individualism-Collectivism

$x$ Peer Evaluation

$-.12^{* *}$

Adj- $R^{2}$

.02

$\mathrm{F}$

${ }^{1}$ Standardized betas reported

Hypothesis two suggested that individualism-collectivism at the team level would moderate the relationship between the independent variable, percent of grade determined by peer evaluation, and instrumental justice effects (i.e., satisfaction with anticipated grade). Hypothesis two was not supported, there was no significant relationship between percent of grade determined by peer evaluation and satisfaction with anticipated grade (see Table 2, column 2).

Hypothesis three suggested a similar moderating relationship between percent of grade determined by peer evaluation and relational justice effects (team-level interactions). Hypothesis three was supported (see Table 2, column 3). The interaction term was significant. The interaction was plotted (see Figure 1), and the results of the plot indicated that percent of grade determined by peer evaluation had a markedly negative effect on collectivistic teams, while it had a marginally positive effect on individualistic teams.

Hypothesis four argued that instrumental procedural justice effects would mediate the relationship between course level procedures (i.e., percent of grade determined by peer evaluation) and student reports of learning (See Table 3, column 1). The results indicated that course-level procedures and instrumental procedural justice effects were 
both significantly related to perceived student learning (step 3), but that justice did not act as a mediator, so this hypothesis was not supported.

TABLE 3

Mediated Regression Results ${ }^{1}$

\begin{tabular}{lll} 
Variables & $\begin{array}{l}\text { H4 } \\
\text { DV: Perceived } \\
\text { Student Learning }\end{array}$ & $\begin{array}{l}\text { H5 } \\
\text { DV: Perceived } \\
\text { Student Learning }\end{array}$ \\
\hline $\begin{array}{lll}\text { Step 1 } \\
\quad \text { Peer Evaluation }\end{array}$ & $.12^{* *}$ & $.12^{* *}$ \\
& & \\
Adj- $R^{2}$ & .01 & .01 \\
F & $12.01^{* *}$ & $12.01^{* *}$ \\
\hline
\end{tabular}

Step 2

Anticipated Grade Satisfaction $\quad .37^{* *}$

Interactions within Teams

$.42^{* *}$

Adj-R

.14

.18

$\mathrm{F}$

$145.77^{* *}$

$164.25^{* *}$

Step 3

Peer Evaluation

$.12^{* *}$

$.14^{* *}$

Anticipated Grade Satisfaction

$.36^{* *}$

Interactions within Teams

$.43^{* *}$

\begin{tabular}{lll} 
Adj-R & \multicolumn{1}{l}{-14} & .19 \\
$\mathrm{~F}$ & $73.02^{* *}$ & $86.31^{* *}$ \\
\hline
\end{tabular}

${ }^{1}$ Standardized betas reported

Hypothesis five suggested that relational justice effects would mediate the relationship between course level procedures (i.e., percent of grade determined by peer evaluation) and student reports of learning (see Table 3, column 2). The results indicated that course-level procedures and relational justice effects were both significantly related to student reports of learning (step 3), but that justice did not act as a mediator, so this hypothesis was not supported. 
Finally, hypothesis six argued that relational procedural justice would be more strongly related to student reports of learning than would instrumental procedural justice. This hypothesis was tested by examining the relative sizes of the $R^{2}$ 's between the two independent variables listed in Step 2 in Table 3. The adjusted- $R^{2}$ for the relational procedural justice regression was .18, while the $R^{2}$ for the instrumental procedural justice regression was .14, suggesting that relational justice does have a stronger impact on student reports of learning than does instrumental justice.

\section{Discussion}

A procedural justice theory of the effects of peer evaluation on student learning in a team environment was partially supported. Our results indicate that for students working on team projects, peer evaluations have implications for their learning. Percent of grade determined by peer evaluation, which is one course level procedure providing students with voice, was positively related to student reports of learning. Furthermore, measures of both instrumental procedural justice and relational procedural justice were positively associated with student reports of learning in a team environment. However, these variables exhibited direct effects rather than serving as mediators in accordance with our hypotheses. Consistent with existing research on procedural justice (e.g., Robbins et al., 2000; Moorman, 1991) relational procedural justice exhibited stronger effects than did instrumental procedural justice.

One particularly interesting finding of this study is the negative relationship between percent of grade determined by peer evaluation and interactional justice for collectivistic teams. While we expected peer evaluations to have a positive influence on students working on individualistic teams, we did not expect them to have a negative influence on those working on collectivistic teams. Perhaps the procedure of peer evaluation clashes with collectivists' social motivations for working in groups. In essence, students on collectivistic teams may view peer evaluations (especially those that account for a large portion of their grade) as breaking team spirit, thus making interactions with team members less motivating and enjoyable for them.

There are several limitations to this study. We used students' subjective perceptions of their own learning rather than more objective indicators of learning such as professor's evaluations (although these are often subjective too). Similarly, since we did not have access to students after the initial data collection, we used satisfaction with anticipated grade rather than satisfaction with actual grade. While the adjusted $R^{2}$ for the instrumental and relational models are good, the adjusted $R^{2}$ for percent of grade determined by peer evaluations alone is low. There are many issues surrounding peer evaluations yet our measure focused only on the extent to which one team member could influence the grade of other team members. Just because an instructor allows students to conduct peer evaluations does not mean that students will use them effectively. For example, a student who decides not to use peer evaluation to penalize team members (because they want to avoid a potential conflict) will not be likely to see them as a mechanism for improving his or her grade or relations within the team. Therefore, research that examines completed peer evaluations for type and amount of 
feedback could provide insight into this topic. Finally, perhaps all peer evaluation procedures are not created equal. As described above, our measure of peer evaluation was quantitative. Including more qualitative aspects of the peer evaluation form and process itself is likely to provide interesting information as well. For example, perhaps justice effects and learning differ in accordance with the number of times peer evaluations are completed during the semester. It is easy to imagine that a mid-term peer evaluation which provides constructive written feedback will improve team functioning, and ultimately learning, more so than one evaluation conducted at the end of the semester

Future research should examine the relationship between peer evaluation and instrumental outcomes other than satisfaction with anticipated grade. For example, a 'fair' distribution of workload among team members could be instrumental to students working on team projects because it allows them to escape unnecessary burdens. We theorized that percent of grade determined by peer evaluation resulted in satisfaction with anticipated grade, in part, because it resulted in decreased social loafing among team members (i.e., a fair distribution of workload). However, it may be that the relationship between percent of grade determined by peer evaluation and student reports of learning is mediated by distribution of workload rather than satisfaction with anticipated grade.

Similarly, since satisfaction with anticipated grade is related to student reports of learning, future research should examine factors leading to this instrumental outcome variable other than percent of grade determined by peer evaluation. For example, a course level procedure of grading on a curve could impact satisfaction with anticipated grade, and thus student reports of learning. Finally, the effect of course level procedures on outcomes other than student learning could be investigated. For example, research exploring the link between course level procedures such as peer evaluation and students' evaluations of their instructors would be especially informative.

This study provides practical implications for deploying teams and utilizing peer evaluation in the classroom environment. By extension, these implications may be appropriate for work environments that rely on teams as a central component in the organization's design. Instructors (in the educational context) and team leaders (in the broader organizational context) can improve the effectiveness of teams by making efforts to foster a favorable justice climate. Justice training may be necessary particularly for teams that lack collectivistic members (low collectivism) (cf Colquitt, Noe \& Jackson, 2002). Attention should be focused on the selection of team members, the expected norms associated with team membership, and preparation and training for working in teams as well as for conducting peer evaluations. To facilitate learning in a team environment, instructors should understand how the procedures they use to administer team projects influence students' perceptions of the fairness of valued outcomes, interactions among team members, and learning of course material. 


\section{References}

Alexander, S., \& Ruderman, A. 1987. The role of procedural and distributive justice in organizational behavior. Social Justice Research, 1: 177-198.

Bacon, D.R., Stewart, K.A. \& Silver, W.S. 1999. Lessons from the best and worst student team experiences: How a teacher can make the difference. Journal of Management Education, 23, 467-488.

Baron, R.M., \& Kenny, D.A. 1986. The moderator-mediator variable distinction in social psychological research: Conceptual, strategic, and statistical considerations. Journal of Personality and Social Psychology, 51: 1173-1182.

Bidder, S.L., Chang, C., and Tyler, T. R. 2001. Procedural justice and retaliation in organizational: Comparing cross-nationally the importance of fair group processes. International Journal of Conflict Management,12: 295-302.

Bies, R. J. 2001. Interactional (in)justice: The sacred and the profane. In J. Greenberg and R. Cropanzano (Eds.), Advances in Organizational Justice. Palo Alto, CA: Stanford University Press, pp. 89-118.

Bies, R. J. and Moag, J. S. 1986. Interactional justice: Communication criteria of fairness. Lewicki, I. R.; Bazerman, M., and Sheppard, B., Editors. Research on Negotiation in Organizations. Greenwich, CT: JAI Press, pp. 43-55.

Bolton, M.K. 1999. The role of coaching in student teams: A "just-in-time approach to learning. Journal of Management Education, 23, 233-250.

Chelte, A.F. 2003. Challenges of Virtual Teams in the Classroom. The Journal of Behavioral and Applied Management ,Winter Vol. 4, No. 2., 122-133.

Chory-Assad, R. 2002. Classroom justice: Perceptions of fairness as a predictor of student motivation, learning, and aggression. Communication Quarterly, 50: 58-78.

Colquitt, J. A., Noe, R. A., And Jackson, C. L. 2002. Justice in teams: Antecedents and consequences of procedural justice climate. Personnel Psychology, 55: 83-110. Cooper, C. L., Dyck, B., \& Frohlich, N. 1992. Improving the effectiveness of gainsharing: The role of fairness and participation. Administrative Science Quarterly, 37: 471-490.

Cox, T., Jr., Lobel, S. A., \& McLeod, P. L. 1991. Effects of ethnic group cultural differences on cooperative and competitive behavior on a group task. Academy of Management Journal, 4: 827-847.

Earley C. P. 1989. Social loafing and collectivism: A comparison of the United States and the People's Republic of China. Administrative Science Quarterly, 34: 565-581. 
Early, C. P. 1993. East meets West meets Mideast: Further explorations of collectivistic and individualistic work groups. Academy of Management Journal, 36, 319-348.

Ettington, D.R. \& Camp, R.R. 2002. Facilitating transfer of skills between group projects and work teams. Journal of Management Education, 26: 356-379.

Fahr, J. L., Podsakoff, P. M., \& Organ, D. W. 1990. Accounting for organizational citizenship behavior: Leader fairness and task scope versus satisfaction. Journal of Management, 16: 705-721

Feichtner, S.B., \& Davis, D.A. 1985. Why some groups fail: A Survey of student learning experiences with learning groups. The Organizational Behavior Teaching Review, 9: 58-71.

Festinger, L. 1957. A theory of cognitive dissonance. Evanston, IL: Row, Peterson. Fishbein, M., \& Ajzen, I. 1975. Belief, attitude, intention, and behavior: An introduction to theory and research. Reading, MA: Addison-Wesley.

Folger, R. \& Konovsky, M. A. 1989. Effects of distributive and procedural justice on reactions to pay raise decisions. Academy of Management Journal, 32: 115-130.

Ghorpade, J. \& Lackritz, J.R. 1998. Equal opportunity in the classroom: Test construction in a diversity-sensitive environment. Journal of Management Education, 22: 4 .

Gibson, C. B., \& Zellmer-Bruhn, M. 2001. Metaphor and meaning: An intercultural analysis of the concept of teamwork. Administrative Science Quarterly, 46: 274-303.

Goldfinch, J., Laybourne, P., MacLeod, L. \& Stewart, S. 1999. Improving group working skills in undergraduate education through employer involvement. Assessment and Evaluation in Higher Education, 24: 41-51.

Greenberg, J. 1990. Looking fair vs being fair: Managing impressions of organizational justice. Research in Organizational Behavior, 12: 111-157.

Houston, M.B \& Bettencourt, L.A. 1999. But that's not fair! An exploratory study of student perceptions of instructor fairness. Journal of Marketing Education, 21 (2): 8496.

James, L.R., Demaree, R.G., \& Wolf, G. 1984. Estimating within-group interrater reliability withi and without response bias. Journal of Applied Psychology, 69: 85-98.

Kane, J. S. \& Lawler, E. E. 1978. Methods of peer assessment. Psychological Bulletin, 85: $555-586$. 
Kirkman, B.L. \& Shapiro, D.L. 2001. The impact of cultural values on job satisfaction and organizational commitment in self-managing work teams: The mediating role of employee resistance. Academy of Management Journal, 44(3): 557-569

Konovsky, M. 2000. Understanding procedural justice and its impact on business organizations. Journal of Management, 26: 489-511.

Korsgaard, M.A., \& Roberson, L. 1995. Procedural justice in performance evaluation: The role of instrumental and non-instrumental voice in performance appraisal discussions. Journal of Management, 21: 657-669

Korsgaard, M. A., Roberson, L., \& Rymph, D. 1998. What motivates fairness? The impact of subordinate assertive communication on managers' interactional fairness. Journal of Applied Psychology, 83: 731-744.

Liden, R. C., Nagao, D. H., \& Parsons, C. K. 1985. Student and faculty attitudes concerning the use of group projects. The Organizational Behavior Teaching Review, $10(4): 32-38$.

Lind, E. A., Kurtz, S., Musante, L., Walker, L., \& Thibaut, J. 1980. Procedure and outcome effects on reactions to adjudicated resolutions of conflicts of interest. Journal of Personality and Social Psychology, 39: 643-653.

Lind, E. A., \& Tyler, T. R. 1988. The social psychology of procedural justice. New York: Plenum.

Marsh, H. W. \& Overall, J. U. 1980. Validity of students' evaluations of teaching effectiveness: Cognitive and affective criteria. Journal of Educational Psychology, 72:468-475.

Michaelson, L.K. \& Kazook, N.M. 1999. Making learning groups effective. Selections: 16, 28-35.

Moorman, R. H. 1991. Relationship between organization justice and organizational citizenship behaviors: Do fairness perceptions influence employee citizenship? Journal of Applied Psychology, 76: 845-855.

Mossholder, K. W., Bennet, N., \& Martin, C. L. 1998. A multilevel analysis of procedural context. Journal of Organizational Behavior, 19: 131-141.

Mullen, B. \& Cooper, C. 1994. The relation between group cohesiveness and performance: An integration. Psychological Bulletin, 115: 210-227.

Mulvey, P. W., Bowes-Sperry, L., \& Klein, H. J. 1998. The effects of perceived loafing and defensive impression management on group effectiveness. Small Group Research, 29: 394-415. 
Murphy, K. R. \& Cleveland, J, N. 1991. Performance Appraisal. Needham Heights, MA: Allyn \& Bacon.

Niehoff, B. P., \& Moorman, R. H. 1993. Justice as a mediator of the relationship between methods of monitoring and organizational citizenship behavior. Academy of Management Journal, 36: 527-556

Olson, M. 1971. The logic of collective action: public goods and the theory of groups. Cambridge MA: Harvard University Press.

O'Reilly, C. A., \& Chatman, J. A. 1986. Organizational commitment and psychological attachment: The effects of compliance, identification, and internalization on prosocial behavior. Journal of Applied Psychology, 71: 492-499.

Robbins, T. L., Summers, T. P., Miller, J. L., \& Hendrix, W. H.; 2000. Using the groupvalue model to explain the role of noninstrumental justice in distinguishing the effects of distributive and procedural justice. Journal of Occupational and Organizational Psychology, $73 ; 511-518$.

Robbins, T. L., \& Fredendall, L. D. 2001. Correlates of team success in higher education. Journal of Social Psychology, 141: $135-137$

Rodabaugh, R. C. \& Kravitz, D. A. 1994. Effects of procedural fairness on student judgments of professors. Journal of Excellence in College Teaching, 5 (2): 67-84.

Shapiro, D.L. 1993. Reconciling theoretical differences among procedural justice researchers by re-evaluating what it means to have one's views "considered:" implications for third-party managers. In. R. Cropanzano (Ed). Justice in the workplace: approaching fairness in human resource management. Hillsdale, NJ: Lawrence Erlbaum. pp 51-78

Shaw, M. E. 1976. Group dynamics: The psychology of small group behavior. New York: McGraw-Hill.

Stubblebine, Patrick C. 2001. Perception and Acceptance of Evaluations by Supervisors and Peers. Current Psychology. Spring, Vol 20: 85-95.

Tata, J. 2001. The influence of national culture on the perceived fairness of grading procedures: A comparison of U.S. and China. Paper presented as part of symposium entitled Fairness in the classroom: Are we practicing what we preach? Academy of Management, Washington D.C.

Thibault, J. \& Walker, L. 1975. Procedural justice: A psychological analysis. Hillsdale, $\mathrm{NJ}$ : Lawrence Erlbaum Associates. 
Tinto, V. 1999. Taking retention seriously: Rethinking the first year of college. NACADA Journal, 19: 5-9.

Tonn, J. C. \& Milledge V. 2002. Team building in an MBA "Gateway" course: Lessons learned. Journal of Management Education, 26: 415-428.

Triandis, H. C., Leung, K., Villareal, M. J., \& Clack, F. L. 1985. Allocentric versus idiocentric tendencies: Convergent and discriminant validation. Journal of Research in Personality, 19: 395-415.

Triandis, H. C., Bontempo, R., Villareal, M. J., Asai, M., \& Lucca, N. 1988. Individualism and collectivism: Cross-cultural perspectives on self-ingroup relationships. Journal of Personality and Social Psychology, 54: 323-338.

Tyler, T. R., Degoey, P., \& Smith, H. 1996. Understanding why the justice of group procedures matters: A test of the psychological dynamics of the group-value model. Journal of Personality and Social Psychology, 70: 913-930.

Wagner III, J. A. 1995. Studies of individualism-collectivism: Effects on cooperation in groups. Academy of Management Journal, 38: 152-172.

Wagner III, J. A. \& Moch, M. K. 1986. Individualism-collectivism: Concept and measurement. Group and Organizational Studies, 11: 280-304.

Watson, W. E., \& Michaelsen, L. K. 1988. Group interaction behaviors that affect performance on an intellective task. Group and Organizational Studies, 13: 495-516.

West, S. G., Aiken, L. S., \& Krull, J. L. 1996. Experimental personality designs:

Analyzing categorical by continuous variable interactions. Journal of Personality, 64: 148.

Wexley, K. N. \& Klimoski, R. J. 1984. Performance Appraisal: An update. In K. Rowland \& G. Ferris (Eds.), Research in Personnel and Human Resources, (Vol. 2, pp. 35-79). Greenwich, CT: JAI. 